\title{
NUREKSAIN KOSABASA SAJERONING BUKU PANGKAJA SARI SMP KELAS IX SANE KANGGEN RING SMP NEGERI 1 SINGARAJA
}

\author{
Ida Ayu Made Sri Widari ${ }^{1}$, Ida Ayu Sukma Wirani ${ }^{1}$, I. B. Rai ${ }^{2}$ \\ Jurusan Pendidikan Bahasa Bali \\ Universitas Pendidikan Ganesha \\ Singaraja, Indonesia \\ e-mail: \{idaayusriwidari@gmail.com, sukma.wirani, \\ bagus.rai\}@undiksha.ac.id
}

\begin{abstract}
KUUB
Tetilikan matetujon nlatarang indik: (1) kaiwangan kosabasa ri sajeroning buku Pangkaja Sari SMP Kelas IX, (2) panampen sisia indik kosabasa sane wenten ring buku, (3) panampen guru indik kaiwangan kosabasa. Wit data sajeroning tetilikan puniki inggih punika kosabasa ring buku Pangkaja Sari SMP Kelas IX. Tetilik nganggen kramaning Studi Pustaka, Dokumentasi miwah Saduwicara. Data tureksa sane kanggen: (1) reduksi data; (2) nyorohang data; (3) pangwedar data; Ian (4) pamicutet. Pikolih tetilikan nureksain kosabasa ring buku Pangkaja Sari SMP Kelas IX, sakadi: (1) kaiwangan kosabasa, sakadi: kaiwangan pangater, pangiring lan kruna tur kaiwangan tata sasuratan (2) penampen sisia indik kosabasa ring buku, sakadi: kosabasanyane meweh tur kari wenten kosabasa sane durung kauningin artosnyane. (3) penampen guru indik kaiwangan kosabasa, sakadi: kosabasanyane sampun becik, nanging kari wenten kosabasa sane durung anut.
\end{abstract}

Kruna jejaton: Kaiwangan, Kosabasa, Buku Pangkaja Sari

\section{ABSTRAK}

Penelitian ini bertujuan menjelaskan: (1) kesalahan kosakata di buku Pangkaja Sari SMP Kelas IX; (2) pendapat siswa tentang kosakata yang ada dibuku; dan (3) pendapat guru tentang kesalahan kosakata. Sumber data dalam penelitian ini adalah kesalahan kosakata yang ada dalam buku Pangkaja Sari SMP Kelas IX. Penelitian ini menggunakan metode studi pustaka, dokumentasi, dan wawancara. Analisis data yang digunakan: (1) reduksi data; (2) menglompokkan data; (3) memaparkan data, dan kesimpulan. Hasil penelitian kesalahan kosakata, antara lain: (1) kesalahan awalan, akhiran dan kata, dan juga kesalahan tata penulisan (2) pendapat siswa tentang kosakata di buku, seperti: kosakatanya sulit dan masih ada yang belum diterjemahkan (3) pendapat guru tentang kesalahan kosakata, seperti: kosakatanya sudah baik, tetapi masih ada kosakata yang belum tepat.

Kata kunci: Kesalahan, Kosakata, Buku Pangkaja Sari 


\begin{abstract}
This study aims to explain: (1) vocabulary errors in the book Pangkaja Sari SMP Class IX; (2) students' opinions about the existing vocabulary in the book; and (3) teachers' opinions on vocabulary errors. Sources of data in this study is the vocabulary errors that exist in the book Pangkaja Sari SMP Class IX. This research uses literature study method, documentation, and interview. Analysis of data used: (1) data reduction; (2) grouping data; (3) describes data, and conclusions. The results of the study of vocabulary errors, among others: (1) misuse of vocabulary, errors of writing and printing errors (2) students' opinions about vocabulary in the book, such as: vocabulary difficult and there are still untranslated (3) teacher opinions about vocabulary errors, such as: the vocabulary is good, but there is still a vocabulary that has not been right.
\end{abstract}

Keywords: Vocabulary Error, Pangkaja Sari Book

\section{PURWAKA}

Manut pasal 28 ayat 1 (ring UUD 1945 sane sampun kaamandemen), iraga mangda prasida nyuksemayang yening kawentenan kaweruhan (pendidikan) banget mautama anggen ngwangun bangsa miwah negara. Rikala ngamargiang tetujon bangsa punika, pastika nenten lempas saking kawentenan piranti sane pacang kanggen ngamargiang tetujon punika. Sane anggen ngamargiang kawentenan piranti punika wantah kawentenan buku ring sekolah, buku dahat mapikenoh tur dahat mautama rikala ngamargiang pangajah-ajah. Yening nenten wenten buku, pastika pacang meweh ngamargiang peplajahan.

Kawentenan buku sane becik pastika banget kaaptiang. Napi malih buku sane dagingnyane madue pikenoh guna sarat pangajah-ajahan (pendidikan karakter) sane prasida nuntun para alitalite ngamargiang parisolah sane becik tur dahat mautama ring sajeroning ngwangun budi pekerti sisia. Napi malih sisia sane kari mlajahang angga ring SD, SMP, SMA/SMK sane dangan pisan kaiusin olih kahanan jagat sane kaon.

Rikala nglaksanayang peplajahan ring kelas, pastika sering kacingak kawentenan buku paket. Kawentenan buku paket punika pastika banget mawiguna tur prasida ngwantu para sisiane mangda sumingkin seleg mlajah. Rikala ngamargiang buku paket punika, pastika sapatutnyane nganggen kosabasa-kosabasa sane becik, baku tur dangan karesepin majeng ring para sisiane. Yening kosabasanyane kari nenten patut, pastika para sisiane pacang meweh ngresepang daging materi ring buku paket, santukan agemannyane kari nenten manut tekening kosabasa Bali sane patut. Basa Bali ngranjing ring peplajahan sane kajejehin olih para sisiane, santukan basannyane meweh. Sane sampun panilik cingakin tur tilikin, mewehnyane punika mawit saking kosabasa Bali sane akidik kauningin punika ngawinang para sisiane meweh ngartosang artos lengkara punika.

Ring kawentenan buku Pangkaja Sari SMP Kelas IX sane kanggen ring SMP Negeri 1 Singaraja puniki akeh taler kapanggihin kaiwangan-kaiwangannyane. Buku punika akehan madue kaiwangankaiwangan indik tata kruna utawi tata lengkara miwah kosabasa-kosabasa utawi lengkara sane nenten patut tekening tata baku basa Bali. Sakadi : "Inggih punika peristiwa sane.......". Kruna peristiwa punika pacang ngawinang para sisia mapineh yening kruna peristiwa punika ngranjing ring soroh kruna basa Bali. Sapatutne kruna peristiwa punika kagentosin antuk kawentenan. Kaiwangan-kaiwangan punika pastika pacang ngranayang para sisia sane ngwacen pacang iwang ngartosang artos lengkara utawi kosabasa punika. Napi malih majeng ring sisia SD, SMP, SMA/SMK sane dangan kaiusin.

Ring penelitian puniki panilik jagi nyelehin indik tata wangun kruna (kruna, frasa lan klausa), tata arti basa Bali (intar-intaran 
kruna (sinonim) lan tungkalikan kruna (antonim) ). Antuk punika, titiang ngambil murda tetilikan nureksain kosabasa ring buku ajar Pangkaja Sari SMP Kelas IX sane kanggen ring SMP Negeri 1 Singaraja.

Panilik ngrereh makudang-kudang pikobet sane mapaiketan sareng dadalan pikobet sane sampun kabahbahang ring ajeng. Pikobet sane sampun karereh minakadi, (1) Sapunapi kaiwangan kosabasa ri sajeroning buku ajar Pangkaja Sari SMP Kelas IX sane kanggen ring SMP Negeri 1 Singaraja? (2) Sapunapi penampen sisia antuk kosabasa sane wenten ri sajeroning buku ajar Pangkaja Sari SMP Kelas IX sane kanggen ring SMP Negeri 1 Singaraja? (3) Sapunapi penampen guru indik kaiwangan kosabasa sane wenten ri sajeroning buku ajar Pangkaja Sari SMP Kelas IX sane kanggen ring SMP Negeri 1 Singaraja? lan (4) Sapunapi kawentenan campur kode sane wenten ring buku Pangkaja Sari SMP Kelas IX?

Saking papat pikobet sane sampun katlatarang ring ajeng, panilik ngawatesin antuk tiga pikobet manten. Ring tetilikan puniki, kaiwangan kosabasa ri sajeroning buku ajar Pangkaja Sari SMP Kelas IX, penampen sisia antuk kosabasa sane wenten ri sajeroning buku ajar Pangkaja Sari SMP Kelas IX,lan penampen guru indik kaiwangan kosabasa sane wenten ri sajeroning buku ajar Pangkaja Sari SMP Kelas IX

Bantang pikobet tetilik: (1) sapunapi kaiwangan kosabasa ri sajeroning buku ajar Pangkaja Sari SMP Kelas IX sane kanggen ring SMP Negeri 1 Singaraja? (2) Sapunapi penampen sisia antuk kosabasa sane wenten ri sajeroning buku ajar Pangkaja Sari SMP Kelas IX sane kanggen ring SMP Negeri 1 Singaraja? Lan (3) sapunapi penampen guru indik kaiwangan kosabasa sane wenten ri sajeroning buku ajar Pangkaja Sari SMP Kelas IX sane kanggen ring SMP Negeri 1 Singaraja?

Tetujon tetilik: (1) Mahbahang miwah nyelehin indik kaiwangan kosabasa ri sajeroning buku ajar Pangkaja Sari SMP Kelas IX sane kanggen ring SMP Negeri 1 Singaraja; (2) Mahbahang miwah nyelehin indik penampen sisia antuk kosabasa ri sajeroning buku ajar Pangkaja Sari SMP Kelas IX sane kanggen ring SMP Negeri 1 Singaraja; lan (3) Mahbahang miwah nyelehin indik penampen guru antuk kaiwangan kosabasa sane wenten ri sajeroning buku ajar Pangkaja Sari SMP Kelas IX sane kanggen ring SMP Negeri 1 Singaraja.

Kawigunan tetilik puniki prasida kabinayang dados kalih, inggih punika kawigunan pamucuk miwah kawigunan panglimbak. Makakalih kawigunan punika sakadi ring sor: (1) kawigunan pamucuk ring tetilik puniki prasida nguningayang indik kosabasa ri sajeroning Buku ajar Pangkaja Sari SMP Kelas IX sane kanggen ring SMP Negeri 1 Singaraja; (2) kawigunan panglimbak sane pacang mawiguna majeng ring sisia, guru, miwah panilik-panilik sane lianan.

Sajeroning ngamargiang tetilikan puniki wenten kalih tetilikan sane mapaiketan pinaka panyanding. Tetilikan punika kanggen sesuluh ri kala panilik ngamargiang tetilikan puniki mangda wenten sane kaanggen dasar utawi tetimbangan. Kalih tetilikan sane kanggen sesuluh olih panilik kakawi olih para sujana. Tetilikan sane kapertama saking Ni Putu Eri Sukerni (2015) sane mamurda "Pangresep Kosa Basa Kruna Aran Sarana Bali Purwa ring Sisia Kelas VII SMP N 2 Singaraja". Siosan saking tetilikan punika wenten taler tetilikan asoroh inggih punika saking Ni Luh Putu Yogi Indus Pratiwi (2016) sane tetilikan nyane mamurda "Nyelehin Kosabasa ri Sajeroning Buku Mekar Wangi SMP Kelas VII sane Kaanggen ring SMP Negeri 2 Gerokgak."

Sudjana (ring Wendra, 2003:14) wenten tigang sumber sane dados pikobet inggih punika : (1) buku utawi pikolih saking tetilikan panilik lianan, (2) studi pendahuluan, miwah (3) angkepan pantaraning tata cara sane kaping siki sareng kaping kalih. Sane dados sumber ring sepat siku-siku puniki inggih punika sane kaping siki.

Buku ajar inggih punika buku sane madaging aji pangweruhan, katedunang saking kompetensi dasar sane wenten 
ring kurikulum taler buku punika kanggen olih sisia rikala mlajah (Andi, 2011: 168).

Mangda prasida kabaos buku ajar punika berkualitas, ring buku ajar punika mangda wenten kriteria-kriteria sane kadadosang dasar ceciren saking buku sane berkualitas.Yening buku punika madaging dasa kreteria sane kaajuang, buku punika prasida kabaos buku sane madue kualitas (Tarigan, 1986: 20-21). Ceciren buku ajar sane becik: buku ajar punika mangda prasida memikat minat sang sane nganggen, buku ajar punika mangda prasida memotivasi para sisia sane nganggen, buku teks mangda madaging ilustrasi sane menarik ati para sisia sane ngawigunaang, buku teks mangda nyingakin saking sisin linguistik mangda buku punika prasida anut sareng kawagedan sisia, Buku teks punika mngda mapaiketan sareng palajahan-palajahan sane siosan, pinih becik yening prasida nulungin pangrencana, sane ngawinang samian dados siki widya sane urut, buku teks punika mangda prasida ngawinang pamargin saking parilaksana sisia sane nganggen, buku teks punika mangda menghindari ambigu, buku teks punika mangda madue sudut pandang sane tatas sane ngawinang pamuputne dados sudut pandang sang sane nganggen punika sane satia, buku teks punika mangda ngicenin penekanan ring nilai-nilai antuk anak cenik lan sane sampun gede lan Buku teks punika mangda prasida ngawinang ngargain pabinaan-pabinaan sang sane nganggen.

Manut Kamus Besar Bahasa Indonesia(2008:736)kosakata:perbendaha raan kata. Kosakata=kosabasa. Kosabasa inggih punika pupulan kruna. Manut Antara (2008:1) kosabasa Bali maarti samian kruna sane wenten ring basa Bali tur pacang mlajahin indik tatawangun kruna sareng artinipune. Sumingkin akeh kruna sane kauningin dadosne sumingkin akeh ide sane kauningin tur prasida kawedarang (Gorys Keraf, 2009: 21).

Cutetnyane, sumingkin akeh kosabasa sane kauningin, kawagedan mabasa pacang sumingkin becik. Kosabasa punika pacang madue teges yening sampun mangge ring reraosan para semeton sane matutur-tuturan.
Dudonan kruna utawi kosabasa punika taler mangda nganutin awig-awig sane kapigumang ring pasang sastra utawi awig-awig basanipun.

Manut Antara (2008:1) wewidangan kosabasa inggih punika : (a) Tata Wangun Kruna : Kruna; frasa; klausa lan (b)Tataarti Basa Bali : Intar-intaran Kruna (sinonim); tungkalikan kruna (akronim).

Manut Kamus Besar Bahasa Indonesia (2008: 634) kata: bentuk terikat. Kata=kruna. Kruna inggih punika wentuk sane sampun kaiket. Manut Suwija lan Gede Manda (2014:32) kruna inggih punika sikian basa sane sampun maderbe arti. Yening nenten maderbe arti durung ngranjing kruna. Antara (2011: 4) maosang ring sajeroning basa Bali punika wenten sane kabaos wangun basa Bali utawi undagan basa Bali sane marupa kruna, frasa, miwah klausa. Kruna ring basa Bali prasida kakepah dados kalih inggih punika (a) Kruna sane nganutin wewangsannyane, lan (b) Kruna nganutin wangunnyane.

Frasa inggih punika lengkaran kasusun antuk makudang-kudang kruna, kelompok kruna, miwah lengkara (Miftahul Kairah lan Sakura Ridwan, 2015: 19). Kelompok kruna sane magenah ring silih sinunggih kawigunan lengkara kawastanin frasa. Nanging nenten samian frasa kasusun antuk kelompok kruna, wenten taler frasa sane kasusun wantah asiki kruna.

Klausa inggih punika wantah jangkepan kruna sane sakirangkirangnyane kawangun antuk jejering lan linging. Parinama klausa mawit saking basa Inggris clause marupa siki lengkara sane kasusun saking silih sinunggil pola dasar lengkara inti (pola dasar kalimat inti) sane madue srana kekalih manut ring basa Indonesia. Klausa puniki kasusun antuk makudang-kudang frasa taler wenten sane maosan klausa tunggal pateh sakadi susunan lengkara tunggal.

Parinama sinonim mawiwit saking kosabasa Yunani Kuno enomo "wastan, nami, adan (nama, BI)" + kruna syn mateges sareng, ajak, (dengan, BI). Kruna sinonim mateges madue arti sane patehAntara (2008:27). Manut (Ernawati Waridah, 2012: 98) lian raos inggih punika 
kruna kakalih sane madue artos pateh nanging wentuknyane malianan.Sakadi, liu lian raosne inggih punika akeh.

Parinama antonim puniki mawit saking kruna basa Yunani Kuno anti sareng anomo sane mateges "wastan, nama" + "melawan". Cutetne kruna antonim maartos "wastane sane lian anggen anak lian" utawi "nama lain untukbenda lain". Sakadi, tegeh tungkalikannyane endep.

Sasuratan Ejaan Basa Bali. Pabligbagan indik ejaan basa Bali manut ring Mendikbud No. 0543a (1987 :8) sakadi ring sor: Panyuratan Aksara Kapital, Panyuratan Aksara Sendeh (Cetak Miring), Panyuratan Kruna lan Ceciren Pepaosan.

\section{KRAMANING TETILIK}

Yening kacingak ring tatujonnyane, tetilikan punika matetujon nelatarang indik data sane kapolihang saking nyelehin marupa buku ajar. Untengnyane, tetilikan puniki nganggen palihan tetilikan deskriptif utamanyane nganggen kramaning deskriptif kualitatif. Wenten lelima papalih paridabdab kramaning tetilik sakadi: (1) pendekatan lan soroh tetilik; Tetilik puniki ngangge pendekatan lan soroh tetilik deskriptif kualitatif; (2) Genah tetilikan puniki ring buku Pangkaja Sari SMP Kelas IX; (3) Wit data sajeroning tetilikan puniki inggih punika kosabasa ring buku Pangkaja Sari Kelas IX warsa 2015, sane katerbitang olih Dwi Jaya Mandiri; (4) mupulang data, Kramaning kanggen mupulang data inggih punika kramaning studi pustaka, saduwicara, dokumentasi, piranti sane kanggen mupulang data inggih punika kartu data; lan (5) data tureksa, Dudonan ring data tureksa punika marupa reduksi data, nyorohnag data, pangwedar data miwah panyutetan.

\section{PIKOLIH LAN TETEPASAN}

Pikolih lan tetepasan tetilik kaiwangan kosabasa sajeroning buku Pangkaja Sari SMP Kelas IX katlatarang ring sor puniki.

Wenten 1 kaiwangan kosabasa indik kaiwangan pangater ring sor puniki jagi katepasin indik kaiwangannyane.
Kaiwangan pangater ring buku Pangkaja Sari SMP Kelas IX mapikolih 1 kruna. Imbanyane inggih punika.

\section{"Ida Bagawanta raris digelis nyawis" (PJS/S6/86)}

Manut Kamus Bali-Indonesia edisi ke 2 Balai Bahasa Denpasar (2008: 201) pangater di nyihnayang galah lan genah, ring kruna "digelis" sane kruna lingganyane "gelis" polih pangater disane dados "digelis". Pangater diring kruna punika nenten nyihnayang genah utawi galah. Dadosnyane pangater di- punika nenten manut yening kajantenang dados pangater ring kruna gelis. Mangda kosabasanyane anut ring lengkara kruna gelis sampunang malih kadagingin pangater. Lengkara sane patut pacang katlatarang ring sor.

"Ida Bagawanta raris gelis nyawis" (PJS/S6/86)

Lianan saking punika kapanggihin 2 kaiwangan pangiring. Imbanyane sakadi.

"Sakewantenan kabecikan punika pastika karasayang waswas,..." (PJS/S1/12)

Manut Dinas Kebudayaan Provinsi Bali (2006: 23) pangiring -an nyantenang lebihan, genah lan asil. Ring kruna "kewantenan" sane kruna lingganyane "kewanten" polih pangiring -an dados "kewantenan". Paniring -an ring kruna punika nenten nyantenang genah, lebihan lan asil. Dadosnyane pangiring -an punika nenten manut yening kajantenang dados pangiring ring kruna kewanten. Mangda kosabasanyane anut ring lengkara kewanten sampunang malih kadagingin pangiring. Lengkara sane patut. 
"Kewanten kabecikan punika pastika karasayang was-was,.." (PJS/S1/12)

Imba sane lianan inggih punika.

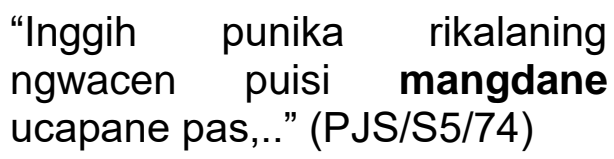

Manut Dinas Kebudayaan Provinsi Bali (2006: 27) pangiring -ne nyihnayang padruen sang sane kabaosang. Ring kruna "mangdane" sane kruna lingganyane "mangda" polih pangiring -ne dados "mangdane". Pangiring -ne ring kruna punika nenten nyihnayang padruen sang sane kabaosang. Dadosnyane pangiring -ne punika nenten manut yening kajantenang dados pangiring ring kruna mangda. Mangda kosabasanyane anut ring lengkara kewanten sampunang malih kadagingin pangiring. Lengkara sane patut.

$\begin{array}{lcc}\text { "Inggih } & \text { punika } & \text { rikalaning } \\ \text { ngwacen } & \text { puisi } & \text { mangda }\end{array}$

Tur kapanggihin 7 kaiwangan ring kruna. Inggih punika.

"Yan luluune tanem ngawinang tanahe mokoh." (PJS/S2/31)

Ring lengkara punika kajantenan wenten kaiwangan sajeroning kruna, santukan ring kruna "mokoh," punika kagentosin antuk kruna "lemek". Santukan suksman lengkara punika indik tanah sane polih luu punika ngawinang subur, kruna subur nenten patut kagentosin antuk kruna "mokoh" krana mateges "gede". Lengkara sane patut pacang katlatarang ring sor.

'Yan luluune tanem ngawinang tanahe lemek" (PJS/S2/31)

Imba sane lianan ngeranjing ring kaiwangan kruna inggih punika

"Inggih punika suara sang pangwacen mangda jelas,.." (PJS/S3/34)
Sajeroning lengkara punika kajantenang wenten kaiwangan ngawigunayang kosabasa, luir ipun ring kruna "jelas" duaning kruna "jelas" punika ngeranjing ring basa Indonesia. Manut Kamus BaliIndonesia (Dinas Pengajaran Provinsi Daerah Tingkat 1 Bali, 1978: 639) sasuratan sane patut inggih punika "sinah". Lengkara sane patut pacang katlatarang ring sor.

"Inggih punika suara sang pangwacen mangda sinah,.." (PJS/S3/34)

Pikolih nyelehin kaiwangan ring tata sasuratan kosabasa, kruna sane ngranjing ring soroh kaiwangan tata sasuratan punika sampun adung sareng teori sasuratan ejaan sane sampun katelatarang ring sepat siku-siku, inggih punika sakadi panampen Kep. Mendikbud No. 0543a warsa 1987 wenten 24 kaiwangan kosabasa indik kaiwangan ring tata sasuratan kosabasa ring sor puniki jagi katepasin indik kaiwangannyane. Kaiwangan tata sasuratan puniki ngingkup kaiwangan panyuratan aksara kapital lan ceciren papaosan.

Panyuratan aksara kapital

Kaiwangan panyuratan aksara kapital kanggen nyurat pangawit gelar kehormatan,keturunan miwah keagamaan sane kasarengin parabnyane, ring tetilikan puniki kapanggihin 2 kruna. Silih sinunggil imbanyane.

"Inggih ratu sang prabhu murdan jagat,..." (PJS/S7/94)

Ring lengkara punika kapolihang kaiwangan panyuratan aksara kapital, krana ring lengkara "ratu sang prabhu,..." sepatutnyane aksara kapertama ring kruna gelar kehormatan punika nganggen aksara kapital. Sane patut "Ratu Sang Prabhu". Manut ring Kep. Mendikbud No. 0543a (1987 :8) gelar kehormatan, keturunan miwah keagamaan sane kasarengin parabnyane ring pangawit kruna nganggen aksara kapital. Lengkara sane patut pacang katlatarang ring sor.

"Inggih Ratu Sang Prabhu
murdan jagat,..."(PJS/S7/94)
Kaiwangan panyuratan aksara kapital kanggen nyurat pangawit wastan geografis. Ring tetilikan puniki 
kapanggihin 2 kruna. Silih sinunggil imbanyane.

"Ida Sang Parbhu Aji Dharma maboros ka gunung alas Lebak Tawa." (PJS/S3/34)

Ring lengkara punika kapolihang kaiwangan panyuratan aksara kapital, krana ring lengkara "gunung alas Lebak Tawa" sepatutnyane aksara kapertama ring kruna wastan geografis punika nganggen aksara kapital sakadi "Gunung Alas Lebak Tawa". Manut ring Kep. Mendikbud No. 0543a (1987 :8) yening nyurat wastan geografis sakadi gunung, danau nganggen aksara kapital. Lengkara sane patut pacang katlatarang ring sor.

"Ida Sang Parbhu Aji Dharma maboros ka Gunung Alas Lebak Tawa." (PJS/S3/34)

Kaiwangan panyuratan aksara kapital kanggen nyurat pangawit kruna wasta, parab utawi pesengan. Ring tetilikan puniki kapanggihin 6 kruna. Silih sinunggil imbanyane ring sor puniki.

"Tiosan ring punika wenten taler $\mathbf{i}$ paksi manyar,.." (PJS/S3/36)

Ring lengkara punika kapolihang kaiwangan panyuratan aksara kapital, krana ring lengkara "i paksi manyar,.." sepatutnyane aksara kapertama ring kruna wasta, parab utawi pesengan punika nganggen aksara kapital sakadi "I Paksi Manyar". Manut ring Kep. Mendikbud No. 0543a (1987 :8) yening nyurat wasta, parab utawi pesengan nganggen aksara kapital. Lengkara sane patut pacang katlatarang ring sor.

"Tiosan ring punika wenten taler I

Paksi Manyar,.." (PJS/S3/36)

Kaiwangan ring ceciren papaosan kapanggihin siki kaiwangan inggih punika kirangnyane tanda hubung ring nyambungang wangun kruna dwi lingga. Ring tetilikan puniki kapanggihin 2 kruna. Silih sinunggilnyane.

"Pidarta pidarta puniki
ketahnyane
$\begin{aligned} & \text { kalaksanayang ring } \\ & \text { (PJS/S1/8) }\end{aligned}$

Ring lengkara punika kapolihang kaiwangan ceciren papaosan inggih punika kirangnyane ceciren panyambung (-), krana ring kruna "Pidarta pidarta" sepatutnyane kruna punika kadagingin antuk ceciren papaosan (tanda hubung) sakadi "pidarta-pidarta". Manut ring Kep. Mendikbud No. 0543a (1987 :8) nyambungang wangun kruna dwi lingga sepatutnyane nganggen tanda hubung. Lengkara sane patut pacang katlatarang ring sor.

"Pidarta-pidarta puniki ketahnyane kalaksanayang ring acara-acara resepsi upacara,.." (PJS/S1/8)

"Sasuratanipun wenten marupa aksara latin wenten taler marupa aksara Bali tetojone mangda alitalite uning ring sakancan sasuratan sane mange ring Bali." (PJS/S8/104)

Ring lengkara punika kajantenan wenten kaiwangan sajeroning tata sasuratan , santukan ring kruna "tetojone" punika patut kasurat "tetujone". Kruna lingga tetujon wit saking kruna lingga tuju sane kadwipurwayang dados tetuju lan polih pangiring -an dados tetujuan, taler kapanggih aksara vokal $\mathrm{u}+\mathrm{a}=0$, punika sane ngawinang kruna tetujuan dados tetujon sane maartos tujuan.

Lengkara sane patut pacang katlatarang ring sor.

"Sasuratanipun wenten marupa aksara latin wenten taler marupa aksara Bali tetujone mangda alitalite uning ring sakancan sasuratan sane mange ring Bali." (PJS/S8/104)

Imba sane lianan rumasuk ring kaiwangan ngawigunayang kosabasa inggih punika

"Tata taler kabaos kabiasaan sane metu ring sajeroning paiketan para janma sane sampun

kacumpuain." (PJS/S5/71)

Ring lengkara punika kajantenan wenten kaiwangan sajeroning cetakan, santukan ring kruna "kacumpuain" punika patut kasurat "kacumpuin". Kruna lingga kacumpuin wit saking kruna lingga cumpu sane ngamolihang pangater kasane dados kacumpu lan polih pangiring in dados kacumpuin sane maartos disetujui.

"Tata taler kabaos kabiasaan sane metu ring sajeroning paiketan para 
janma sane sampun kacumpuin." (PJS/S5/71)

Lianan ring punika, panilik ngamargiang saduwicara majeng sisia kelas IX ring sekolah SMP Negeri 1 Singaraja. Saduwicara puniki kalaksanayang matetujon mangda data sane kapolihang pastika tekening sane ka tilikin. Lianan teken punika mangda panilik uning napi manten panampen parasisia SMP Negeri 1 Singaraja sane nganggen ageman buku Pangkaja Sari SMP Kelas IX:

Manut penampen para sisia kelas IX, ngenenin indik buku ajar Pangkaja Sari puniki sampun becik materinyane, tur prasida ngwantu para sisiane mlajahin indik basa Bali. Nanging wenten kaiwangannyane sekadi kirangnyane contoh-contoh soal, kosabasanyane meweh, tur kari wenten kosabasa sane durung kaojahang. Kawentenan kosabasa sane karasayang meweh ring sisia sane dahat ngaweruhin pangresep sisia indik daging wacane ring buku.

Rikala ngarereh data puniki, panilik nglaksanayang saduwicara majeng guru kelas IX ring sekolah SMP Negeri 1 Singaraja. Saduwicara puniki kalaksanayang matetujon mangda data sane kapolihang pastika tekening sane katilikin. Lianan teken punika mangda panilik uning panampen guru sane ngajahain basa Bali. Ring sor pacang katlatarang indik cutetan utawi ringkesan panampen saking guru basa Bali kelas IX sane nganggen buku Pangkaja Sari :

Manut guru basa Bali ring kelas IX, daging buku ajar Pangkaja Sari sampun manut pantaraning kurikulum, sakemaon wenten materi sane nenten patut akidik. Yening kawentenan kosabasanyane sampun becik, nanging wenten kosabasa sane nenten tepat.

Indik kaiwangan kosabasa sane wenten sampun mresidayang ketepasin, yening ngajahin ritatkala nyelasang kebecikang malih kapining para sisia. Nanging kaiwangan kosabasa puniki krana penulis durung uning indik kosabasa Bali sane patut.

Implikasi sane kapolihang, buku ajar sane becik madue ceciren mangda prasida memikat minat sang sane nganggen, mangda prasida memotivasi para sisia sane nganggen, madaging ilustrasi sane menarik ati para sisia sane ngawigunaang, mangda mapaiketan sareng palajahan-palajahan sane siosan, lan buku teks punika mangda ngicenin penekanan ring nilai-nilai antuk anak cenik lan sane sampun gede lan buku teks punika mangda prasida ngawinang ngargain pabinaanpabinaan sang sane nganggen. Manut observasi sane sampun kalaksanayang ring SMP (Sekolah Menengah Pertama) sane wenten ring Kota Singaraja, wantah buku ageman Pangkaja Sari kemanten sane kanggen. Santukan manut guru basa Bali ring SMP Negeri 1 Singaraja, buku Pangkaja Sari puniki dagingnyane jangkep tur manut ring kurikulum sane kanggen ring sekolah inggih punika kurikulum 2013. Yening binayang buku puniki akeh kapanggihin tata sasuratan sane iwang, saking kaiwangan kosabasa ring buku Pangkaja Sari punika, ngawinang para sisia meweh nelebin daging sasuratan sane wenten ring buku. Kaiwangan punika taler ngapiambengin para sisia rikala mlajahin daging buku ajar Pangkaja Sari. Pikolih tetilikan puniki kaaptiang mangda ngicenin rerawatan majeng ring pangawi buku mangda nyelehin lan nginutin malih kosabasa sane wenten ring buku mangda sayan patut sajeroning tata sasuratannyane. Boya ja majeng ring pangawi buku Pangkaja Sari kemanten, nanging majeng ring Pangawi buku-buku peplajahan lianan sane kanggen ring sekolah-sekolah. Buku-buku punika sapatutnyane mangda nguratiang indik kosabasanyane sane wenten ring sakancan wacana, intruksi kerja tur soal-soal lan nguratiang tata sasuratannyane mangda nenten akeh wenten kaiwangan. Mangda para sisia 
dangan ngresepin indik daging buku punika.

\section{PAMUPUT}

Sajeroning ringkesan ring tetilikan puniki pacang katelatarang indik (1) adyaya I; (2) adyaya II; (3) adyaya III; lan (4) adyaya IV. Indike punika pacang katelatarang ring sor.

Adyaya I pinaka purwaka, kajantenang madaging dadalan pikobet, ngrereh pikobet, ngwatesin pikobet, bantang pikobet, tetujon tetilikan lan kawigunan tetilikan. Dadalan pikobet nelatarang indik dasar pepineh panilik ngaryanin utawi nilikin tetilikan puniki. Ngrereh pikobet nelatarang indik panilik ngrereh makudang-kudang pikobet sane mapaiketan sareng dadalan pikobet. Ngwatesin pikobet nelatarang indik panilik ngwatesin malih pikobet sane sampun karereh. Bantang pikobet ring tetilikan puniki inggih punika kaiwangan kosabasa ri sajeroning buku ajar Pangkaja Sari SMP Kelas IX, penampen sisia antuk kosabasa sane wenten ri sajeroning buku ajar Pangkaja Sari SMP Kelas IX, lan penampen guru indik kaiwangan kosabasa sane wenten ri sajeroning buku ajar Pangkaja Sari SMP Kelas IX. Tetujon tetilikan inggih punika mahbahang miwah nyelehin indik kaiwangan kosabasa ri sajeroning buku ajar Pangkaja Sari SMP Kelas IX, penampen sisia antuk kosabasa ri sajeroning buku ajar Pangkaja Sari SMP Kelas IX, lan penampen guru antuk kaiwangan kosabasa sane wenten ri sajeroning buku ajar Pangkaja Sari SMP Kelas IX. Kawigunan tetilikan inggih punika kawigunan pamucuk (teoritis) lan kawigunan panglimbak (praktis).

Adyaya II pinaka sepat siku-siku, kajantenang madaging tetilikan sane asoroh, sepat siku-siku, lan model tetilikan. Tetilikan sane asoroh nelatarang indik sajeroning ngamargiang tetilikan puniki wenten kalih tetilikan sane mapaiketan pinaka panyanding. Sepat siku-siku sane kaanggen inggih punika artos buku ajar, artos kosabasa, sasuratan ejaan basa Bali, lan artos kruna. Model tetilikan katlatarang antuk bagan.

Adyaya III pinaka kramaning tetilik, kajantenang madaging pendekatan lan soroh tetilikan, genah tetilikan, wit data, parikrama mupulang data, lan data tureksa. Pendekatan lan soroh tetilikan sajeroning tetilikan puniki nganggen kramaning deskriptif kualitatif. Genah tetilikan puniki ring buku Pangkaja Sari SMP Kelas IX. Wit data sajeroning tetilikan puniki inggih punika kosabasa sane wenten ring buku Pangkaja Sari SMP Kelas IX. Parikrama mupulang data sajeroning tetilikan puniki inggih punika kramaning parikrama studi pustaka, dokumentasi, lan saduwicara. Pamargi sane pacang kalaksanayang ring sajeroning nureksain data inggih punika reduksi data, nyorohang data, pangwedar data, lan pamicutet.

Adyaya IV pinaka pikolih lan tetepasan, kajantenang madaging pikolih lan tetepasan saking kaiwangan kosabasa, penampen sisia antuk kosabasa, lan penampen guru indik kaiwangan kosabasa ring buku ajar Pangkaja Sari SMP Kelas IX.

Panyutetan indik pikolih tetilikan sane sampun kalaksanayang inggih punika Kawentenan kosabasa sajeroning buku Pangkaja Sari SMP Kelas IX sane kanggen ring SMP Negeri 1 Singaraja sampun becik indik materi-materinyane, nanging kari akeh kakirangannyane sekadi kaiwanganpangater, pangiring, kruna tur kaiwangan ring tata sasuratan.

Penampen para sisia kelas IX, ngenenin indik buku ajar Pangkaja Sari puniki sampun becik materinyane, tur prasida ngwantu para sisiane mlajahin indik basa Bali. Nanging wenten kaiwangannyane sekadi kirangnyane contoh-contoh soal, kosabasanyane meweh, tur kari wenten kosabasa sane durung kaojahang.

Manut guru basa Bali ring kelas IX, daging buku ajar Pangkaja Sari sampun manut pantaraning kurikulum, sakemaon wenten materi sane nenten patut akidik. Yening kawentenan kosabasanyane sampun becik, nanging wenten kosabasa sane nenten tepat.

Indik kaiwangan kosabasa sane wenten sampun mresidayang keatasin, yening ngajahin nyelasang keralat malih kapining para sisia. Nanging kaiwangan kosabasa puniki krana durung uning nyane penulis indik basa Bali sane pinih becik. 
Piteket kawedarang majeng ring: (1) Mangda setata teleb mlajahin basa Bali utaminyane kosabasa Bali, mangda sisia nenten iwang ngresepang yening wenten kaiwangan kosabasa. Yening sisia sampun uning kosabasa sinah pacang prasida mabebaosan lan nyurat kosabasa Bali sane becik; (2) Ritatkala ngajahin mangdsa nenten nganggen siki buku kemanten, mabuat pisan mangda guru punika taler nganggen refrensi buku sane lian, pangaptinyane yening wenten kaiwangan kosabasa ring buku mangda prasida kabecikang malih kosabasanyane mangda anut lan nenten ngapiambengin par sisia; (3) Majeng ring panilik salanturnyane sane jagi nyelehin indik kosabasa Bali, mangda tetilikan puniki prasida kanggen sasuluh/pakeling utawi tetimbangan rikala nilikin tetilikan asoroh lan nyelehin buku paket sane kanggen ring sekolah-sekolah sane lianan manut wewidangan kaweruhan sane tiosan; (4) Mangda prasida ngicenin rerawatan majeng ring pangawi buku, mangda nguratiang indik kosabasanyane sane wenten ring sakancan wacana, intruksi kerja tur soal-soal sane madaging ring buku punika lan pangetikan ring wacana punika taler kacingakin malih mangda nenten akehan iwang ring pangetikan.

\section{KAPUSTAKAAN}

Antara, I Gusti Putu. 2008. Kosabasa Bali: Singaraja: Universitas Pendidikan Ganesha.

Dinas Kebudayaan Provinsi Bali. 2006. Tata Basa Bali. Denpasar: Dinas Kebudayaan Provinsi Bali.

Kairah, Miftahul lan Sakura Ridwan. 2015. Sintaksis. Jakarta: Bumi Aksara.
Kamus Bali-Indonesia, edisi kedua Balai Bahasa Denpasar. 2008. Denpasar: Yayasan Pustaka Nusatama.

Kamus Besar Bahasa Indonesia,edisi keempat. 2008. Jakarta: Balai Pustaka.

Kep. Mendikbud No. 0543a. 1987. Ejaan yang Disempurnakan. Jakarta: Bumi Aksara.

Keraf, Gorys. 1985. Diksi dan Gaya Bahasa. Jakarta: PT.Gramedia.

Prastowo, Andi. 2011. Panduan Kreatif Membuat Bahan Ajar Inovatif Menciptakan Metode Pembelajaran yang Menarik dan Mengesankan. Jogjakarta: DIVA Press.

Pratiwi, Ni Luh Putu Yogi Indus. 2016. Nyelehin Kosabasa ri Sajeroning Buku Mekar Wangi SMP Kelas VIII sane Kanggen ring SMP Negeri 2 Gerokgak. Skripsi (nenten katerbitang) Jurusan Pendidikan Bahasa Bali, FBS UNDIKSHA.

Sukerni, Ni Putu Eri. 2015. Pangresep Kosabasa Kruna Aran Sarana Bali Purwa ring Sisia Kelas VII SMP N 2 Singaraja. Skripsi (nenten katerbitang). Jurusan PendidikanBahasa Bali, FBS UNDIKSHA.

Suwija, I Nyoman dkk. 2014. Tata Titi Mabaos Bali. Denpasar: Pelawa Sari.

Tarigan, Prof.Dr.Henry Guntur dkk. 1986. Telaah Buku Teks Bahasa Indonesia. Bandung: Angkasa.

UUD 1945. UUD'45 yang sudah diamandemen. Surabaya: Apollo. UNDIKSHA. 2015. Pedoman Penulisan Karya Ilmiah Tugas Akhir dan Skripsi.Singaraja: UNDIKSHA.

Waridah, Ernawati. 2012. Ejaan Yang Disempurnakan dan Seputar Kebahasa-Indonesiaan. Bandung: Ruang Kata.

Wendra, I Wayan. 2014. Penulisan Karya IImiah. Singaraja: Undiksha. 